\title{
Parálisis del VI par craneal asociado con Infección con Chikungunya
}

\author{
Andrea Tufiño[a], David Gaus[b], Diego Herrera[c] \\ a. Posgrado Medicina Familiar PUCE \\ b. Andean Health and Develoment \\ c. Saludesa - Santo Domingo \\ PRÁCTICA FAMILIAR RURAL | Vol.2 | No.3 | Noviembre 2017| Recibido: \\ 22/08/2017| Aprobado: 31/09/2017 \\ Como citar este artículo \\ Tufiño A, Gaus D, Herrera D, Parálisis del VI par craneal asociado con \\ Infección con Chikungunya. Práctica Familiar Rural. 2018. noviembre; 3(2).
}

\section{RESUMEN}

Introducción: Las lesiones oculares pueden ser una complicación que presenten pacientes con infección por Chikungunya. Los médicos que atienden a pacientes expuestos a Chikungunya deben estar conscientes de las complicaciones además de las ya conocidas, estas oculares, que pueden presentar durante la infección aguda hasta meses después.

Objetivo: fortalecer conocimientos y motivar a un adecuado registro, además, dar a conocer la importancia del manejo eficaz y oportuno debido a la ausencia de antídoto.

Casos: Reportamos dos casos de parálisis del VI par craneal durante una epidemia de Chikungunya en Ecuador rural en 2017. Los dos pacientes acudieron varios meses después de la infección aguda debido a su lejanía con el centro hospitalario.

Conclusión: Pacientes con oftalmolplejia, que habitan en zonas de transmisión del virus Chikungunya, se debe sospechar Chikungunya como causa, especialmente en la ausencia de otros factores de riesgo.

Palabras clave: Chikungunya, paralilis del sexto par. 


\title{
Clinical Case: Cranial Nerve Palsy Associated with Chikungunya infection
}

\begin{abstract}
ABATRACT
Introduction: Eye injuries can be a complication of patients with Chikungunya infection. Physicians who care for patients exposed to Chikungunya should be aware of the complications in addition to those already known. These ocular lesions may occur during acute infection or up to several months later.
\end{abstract}

Objective: to strengthen knowledge and motivate an adequate registry, in addition, to make known the importance of effective and timely management due to the absence of an antidote.

Cases: We report two cases of paralysis of the sixth cranial nerve during a Chikungunya epidemic in rural Ecuador in 2017. The two patients were attended several months after the acute infection due to their distance from the hospital center.

Conclusion: Patients with ophthalmoplegia, who live in areas of Chikungunya virus transmission, should be suspected as Chikungunya cases, especially in the absence of other risk factors.

Keywords: Chikungunya, paralilis of the sixth pair

\section{Introducción}

Chikungunya es un arbovirus transmitido principalmente por Aedes aegypti que llegó a America Latina en los últimos 5 años (Magurano, 2015). En Ecuador se encuentra un brote en áreas tropicales y subtropicales desde 2016.(MSP,2016)

El compromiso ocular en Chikungunya no es común. Lalitha, et al reporta una epidemia en India de algunos trastornos oculares relacionados con Chikungunya, incluyendo: uveítis, neuritis óptica, queratitis dendrítica, y parálisis de pares oculares como III y XI (Lalitha, 2007).

Presentamos dos pacientes que acudieron al Hospital Pedro Vicente Maldonado y Hospital Hesburgh con parálisis unilateral del VI par craneal durante el brote.

\section{Presentación del caso}

\section{PACIENTES}

\section{Primer Caso}

Paciente masculino de 76 años de edad, presenta antecedentes de HTA y Accidente Cerebrovascular Isquémico hace 2 años sin secuelas neurológicas, hace tres meses, cuadro clínico de 5 días de fiebre, cefalea, y artralgias. Acude al hospital por presentar 2 semanas, refiriendo dolor en región lumbar de predominio derecho, que no cede a uso de analgésico. En la revisión actual de sistemas, presenta desde hace un mes diplopía de inicio súbito, sin trauma ocular o cefalea. 
Al examen físico TA. $160 / 70 \quad$ FC 58 FR. $20 \quad$ T. $36 .{ }^{\circ} \mathrm{C}$

Cabeza no aparenta lesiones ni deformidades, ojos. Al realizar movimientos de abducción de ojo derecho se observa parálisis, resto de movimientos aducción rotación interna, conservados.

\section{Paralisis de sexto par}

Corazón: rítmico en dos tonos sin soplos, pulmones murmullo vesicular conservado, Región lumbar doloroso a la palpación en región paravertebral derecha, movimientos de flexión y extensión limitados, además al valorar cadera con rotación externa dolorosa.

Examen neurológico; Romberg negativo, marcha disbasica, coordinación dedo nariz, palma dorso conservado.

Se realizan exámenes complementarios hematológico con leucocitos 9,800 segmentados: 69\% linfocitos: $23 \%$ hemoglobina $13.2 \mathrm{~g} / \mathrm{dl}$ Hematocrito $43 \%$ plaquetas 24.4000 , PCR; $<2.5 \mathrm{~g} / \mathrm{dl}$ glucosa $94 \mathrm{mg}$ procalcitonina $<0.10$

Tomografía de cráneo: fosa posterior y cuarto ventrículos normales, supratentorialmente, parénquima cerebral, homogéneo, no se observan lesiones o colecciones. Pequeñas imágenes hiperdensas bilaterales de ganglios de la base. Buena diferenciación de sustancia gris y blanca. Elementos de la línea media conservados, surcos de la convexidad y sistema cisterno ventricular normal, calcificaciones fisiológicas de abéñula, pineal y plexos coroides

Evolución clínica: paciente que permaneció en hospitalización por 4 días con evolución clínica favorable al uso de corticoides sistémicos (Dexametasona) $4 \mathrm{mg}$ cada 6 horas endovenoso, por 3 días en hospitalización y luego con prednisona $50 \mathrm{mg}$. vía oral por 4 días más. El dolor y la oftalmoplejia evolucionaron favorablemente, luego de dos semanas la parálisis desapareció por completo.

\section{Segundo Caso}

Paciente de 28 años de edad refiere como antecedentes de importancia un cuadro de fiebre, cefalea, y artralgias severas que duró siete días, hace ocho meses. El motivo de su consulta es 4 meses de diplopía y una semana de cefalea hemicraneana izquierda con EVA 10/10 se irradia a 
región ocular izquierda, visión borrosa, nausea que no llega al vomito menciona que acudió a centro de salud sin mejoría. Niega traumatismos o pérdida de la conciencia. No es diabético ni hipertenso.

\section{Examen físico TA: 110/70 FC: $78 \quad$ FR: $20 \quad$ T: $37.1 \quad$ Sat: $98 \%$}

Ojos: parpados normales; limitación para mirada externa de ojo derecho, pupilas isocoricas, fotoreactivas, conjuntivas rosadas, Fondo normal, Boca. Mucosas orales húmedas Orofaringe: no congestiva, reflejo nauseoso presente, cuello: no adenopatías, motilidad conservada, no signos meníngeos. Corazón, Pulmones, Abdomen: normal.

Examen neurológico: Glasgow 15/15, compromiso de sexto par craneal del lado izquierdo, sensibilidad conservada, Romberg negativo, coordinación dedo nariz, palma dorso conservado, marcha normal.

\section{parálisis del sexto par caso 2}

Se realizaron estudios de laboratorio en los cuales no se evidencia leucocitosis no anemia no trombocitopenia con reactantes de fase aguda negativa. TAC de cabeza negativa sin hallazgos relevantes.

Evolución: Se decide iniciar tratamiento con corticoides sistémicos con Prednisona 60mg VO QD evidenciándose una mejoría parcial con sus movimientos en la evolución y una recuperación total de los movimientos una semana después en consulta externa.

\section{Discusión}

Varias manifestaciones oculares de Chikungunya están descritos en la literatura, incluyendo: uveítis, neuritis óptica, retinitis, queratitis, y parálisis de músculos extra-oculares. (Lalitha 2007) (Economopoulou 2008) Estas manifestaciones pueden presentar en la fase aguda o hasta varios meses después. (Lalitha 2007, Mahendradas 2008). Los dos pacientes presentaron con parálisis del VI par craneal meses después de su infección aguda de Chikungunya.

Las lesiones del VI par craneal pueden ubicarse en distintos niveles del recorrido del nervio, no siempre identificándose el lugar exacto. El sexto nervio es un caso en el punto porque tiene un curso largo y relativamente aislado después de que sale del tronco cerebral, sube el clivus y pasa a 
través del seno cavernoso (Shoja 2014). Esto permite que ciertos tumores afecten a ambos sextos nervios antes de que cualquier otra parte del cerebro se vea afectada. Las causas pueden ser: Traumática (fracturas en base del cráneo que afecten el segmento petroso del sexto par, fracturas de mastoides, hipertensión endocraneana); Neoplásica; Infecciosa (meningoencefalitis, meningitis por $\mathrm{Tb}$ ); Vascular (diabetes, hipertensión arterial, vasculitis); Idiopática; Misceláneas (trombosis seno sagital y transverso, schwanoma, carcinoma nasofaríngeo, metástasis, esclerosis múltiple en adultos jóvenes, Síndrome de Miller Fisher y toxicidad: vincristina , ciclosporina) (Elder 2016)

No hubo una confirmación serológica del diagnóstico de Chikungunya por falta de disponibilidad a nivel nacional de la prueba de Biología Molecular, pero los pacientes demostraron las típicas características de la enfermedad viral durante una epidemia que fue confirmada serológicamente por el estado Ecuatoriano. No se realizo' punción lumbar en ninguno de los dos pacientes por falta de signos meníngeos. Encefalitis asociado con Chikungunya esta' reportada, y no podemos descartar un leve aumento de presión intracraneal secundario a una encefalitis sutil. Los dos pacientes lograron una recuperación total de su déficit neurológico que sugiere una causa isquémica microvascular (Bruce 2007).

Reconocemos que un parálisis del VI par craneal asociado con Chikungunya es un diagnóstico de exclusión porque no se puede establecer evidencia firma, pero apoyamos el diagnostico en los dos pacientes. Chikungunya es un alphavirus neurotrópico que induce algunos moléculas proinflamatorios y citoquinas que tienen efectos neurotóxicos directos e indirectos (Benzekri 2016).

En pacientes con ciertas lesiones oculares como uveítis, neuritis óptica, retinitis, queratitis, y parálisis de músculos extra-oculares en zonas de transmisión del virus Chikungunya, se debe sospechar Chikungunya como causa, especialmente en la ausencia de otros factores de riesgo.

\section{Referencias bibliográficas}

Economopoulou A, Domínguez M, Helynck A, et al. Atypical Chikungunya virus infections: clinical manifestations, mortality and risk factors for severe disease during the 2005-2006 outbreak on Réunion. Epidemiol Infect. 2008;11:1-8.

Mittal A, Mittal S, Bharati MJ, et al. Optic neuritis associated with Chikungunya virus infection in South India. Arch Ophthalmol. 2007;125:1381-1386.

Lalitha P, Rathinam S, Banushree K, et al. Ocular involvement associated with an epidemic outbreak of Chikungunya virus infection. Am J Ophthalmol. 2007;144:552-556.

Mahendradas P, Ranganna S, Shetty R. Ocular manifestations associated with Chikungunya. Ophthalmology. 2008;115:287-291

Benzekri R, Hage R, Merle H. Third cranial nerve palsy in the setting of Chikungunya Virus Infection. Am J Trop Med Hyg. 2016 Jul 6; 95(1): 180-81

Bruce B, Biousse V, Newman N. Third nerve palsies. Semin Neurol 2007; 27:257-268

Shoja M, Oyesiku N. Clinical Anatomy of the cranial nerves. Clin Anat. 2014 Jan; 27(1): 2-3. doi $10.1002 /$ ca.22365

Elder C, Hailine C, Galetta S, Balcer L, Rucker J. Isoltaed Abducens Nerve Palsy: an update on evaluation and diagnosis. Curr Neurol Neurosci Rep. 2016 Aug; 16(8):69 